\title{
Smoking Cessation for Pregnant Women
}

\section{Current Canadian Programs and Future Development}

Karen M. Devries, BSc

Lorraine J. Greaves, PhD

$\mathrm{P}$ regnant smokers comprise a distinct subgroup for smoking cessation intervention. Today, between $20 \%$ and $30 \%$ of women smoke during pregnancy. ${ }^{1,2}$ Among the many who do manage to quit successfully during the prenatal period, $70-90 \%$ have relapsed by one year postpartum ${ }^{2}$ despite a prolonged period of abstinence. Clearly, intense efforts in encouraging smoking cessation during pregnancy have resulted in, at best, temporary abstinence, but have failed to generate long-term improvements in women's health. More effective smoking cessation programs must be developed to help pregnant and postpartum women quit and maintain their abstinence.

Within the category of 'pregnant smoker', diverse subpopulations exist, including Aboriginal and other cultural groups, low-income women, teenage girls and heavy smokers. Another important group that merits increased attention is the 'spontaneous quitter'. These are pregnant women who are former smokers, having quit either before entering prenatal care or in early pregnancy. Given the high rates of relapse observed postpartum, the programming for 'pregnant smokers' needs to be expanded to include these women and girls. The differing social and economic realities experienced by all of these groups lead to unique trajectories of tobacco cessation. However, in Canada, few smoking cessation programs are available that address the unique dynamics of cessation and relapse in these diverse subpopulations of pregnant smokers, and little material exists at all to assist postpartum women quit smoking.

This article summarizes the types of programs currently available to Canadian pregnant smokers, and suggests directions for future program development. As part of a larger project investigating and suggesting better practices in this field, program materials and information (including evaluations) pertaining to pregnant smokers were sought from over 50 agencies in Canada and the US. A multitude of programs for women and for specific groups of women, such as Aboriginals, were obtained, but only nine programs were specifically designed for pregnant and/or postpartum women and/or girls (see Table I). Of these nine, four provided evaluation data. Table II lists additional resources aimed at healthcare providers.

\section{Program landscape}

Of the few Canadian programs explicitly targeted to pregnant and postpartum smokers, most are based on popular behavioural change techniques such as motivational interviewing $^{3}$ and the Transtheoretical Model. ${ }^{4}$ Many also include components on media education, and some include group counselling. While several programs acknowledge partner smoking as important, little in the way of specific interactive components for partners is avail-

British Columbia Centre of Excellence for Women's Health, Vancouver, BC

Correspondence and reprint requests: Lorraine Greaves, BCCEWH, at BC Women's Hospital, E3114500 Oak Street, Vancouver, BC V6H 3N1, Tel: 604-875-2633, Fax: 604-875-3716, E-mail: Igreaves@cw.bc.ca

Acknowledgements: This article stems from a larger work, "Expecting to Quit: A Best Practices Review of Smoking Cessation Interventions for Pregnant and Postpartum Women and Girls," funded by Health Canada. The project team consisted of: Drs. Lorraine Greaves and Renee Cormier and Ms. Karen Devries, BC Centre of Excellence for Women's Health; Drs. Joan Bottorff and Joy Johnson, University of British Columbia; Dr. Susan Kirkland, Dalhousie University; and Dr. David Aboussafy, Psychologist, Clinical Coordinator, Counseling Services, University of British Columbia able. The highly critical issue of postpartum relapse is ignored almost entirely, and is not the focus of any tailored component. Similarly, tailored materials for specific subpopulations of pregnant smokers especially spontaneous quitters, teenagers and Aboriginal women - are almost entirely lacking.

Among the most visible organizations providing resources to pregnant smokers wishing to quit are the Canadian Cancer Society (CCS), Health Canada, and the Lung Association. Information about the health effects of smoking during pregnancy, as well as a contact list for smoking cessation programs are also readily available through Health Canada. Unfortunately, in many cases it is difficult to gain access to existing program materials (beyond informational pamphlets) specifically for pregnant smokers. For almost all organizations providing assistance in our research, staff awareness of the range of materials available, even from within their own organization, was a problem.

\section{Directions for programming in Canada}

Some important directions for creating more effective programming in Canada are summarized in Table III. In addition to these approaches, two priorities are listed below.

1. Recognize differences in subpopulations of pregnant smokers. Perhaps the most important step Canadian programmers can take involves increasing awareness of the distinct differences between pregnant and non-pregnant smokers, and further, between different kinds of 'pregnant smokers'. Each subpopulation of pregnant smoker - for example, Aboriginal women, teenaged girls, spontaneous quitters, heavy smokers and low-income women - experiences the trajectory and context of tobacco cessation differently, and 'pregnant smokers' as a group are distinct from other groups of smokers. Key to this difference is the presence of the fetus as an external and time-limited motivation for cessation. Although preliminary efforts have been made, future programs need to focus on these important inter- and intra-group differences.

2. Increase awareness of existing programs. Increased awareness of extant programs should become an immediate priority. 
TABLE I

Programs Available for Pregnant Smokers in Canada

Program

Baby's Coming,

Baby's Home

Great Start

Holding Our Own

New Start

Start Quit, Stay Quit

(Technical Report ${ }^{6}$ )

Stopping When You're

Ready

$\left(\right.$ Evaluation$^{7}$ )

Smoke Free Journey

(Evaluation $^{8}$ )

Kick Butt for 2

$\left(\right.$ Evaluation $\left.^{9}\right)$

Freedom from Smoking for You and Your Baby $\left(\right.$ Evaluation $^{10}$ )

\section{Source}

Nova Scotia Lung

Association

www.greatstart.org [US]

Walpole Island Health Unit

Canadian Cancer Society

Windsor-Essex Health Unit, ON

Windsor-Essex Health

Unit, ON

Northern Family Health Society

St. Mary's Home,

Ottawa, ON

Available from any provincial

Lung association; developed

by American Lung Association
Target Population

Pregnant smokers

("low-income")

Pregnant smokers

Pregnant Aboriginal women/ Women of colour smokers

Pregnant smokers

Pregnant smokers

Pregnant and postpartum smokers

Pregnant Aboriginal women smokers; pregnant smokers

Teenage/Young women

Pregnant smokers
Provider

Health professionals, educators and other resource people

Self-help

Video (encourages use of peer support group)

Self-help (available online)

Self-help

Self-help (counselling)

Trained counsellors

Group facilitators

\section{Intervention Components}

Information; tailored information (video); to be used in conjunction with counselling

Tailored information (Great Start Self-Help Guide)

Tailored information (video)

Tailored information (self-help guide)

Tailored information for partners and pregnant smokers; designed to be used in conjunction with counselling

Tailored information; designed to be used in conjunction with counselling

Information; counselling

Self-help
Stage-based cessation manual
Based on the current, available evidence in the literature, behaviourally oriented cessation programs based on the Stages of Change can successfully help some women quit, and such programs which already exist should be made more accessible to low-income and rural women whose cessation options may be more limited. However, some research suggests that the Stages of Change model may not adequately characterize the motivations of pregnant smokers with respect to tobacco cessation ${ }^{5}$ and is therefore less applicable to pregnant women.

In summary, while there has been a vast effort in promoting tobacco cessation during pregnancy, the results have been marginal. A wider understanding of the role that social and economic context plays in patterns of cessation and relapse among pregnant and postpartum women is urgently needed to adequately inform improved programming.

\section{REFERENCES}

1. Coleman GJ, Joyce T. Trends in smoking before, during and after pregnancy in ten states. $A m J$ Prev Med 2003;24(1):29-35.

2. Klesges LM, Johnson KC, Ward KD, Barnard M. Smoking cessation in pregnant women.

\section{TABLE II}

\section{Programs for Health Care Providers}

Program

Asking to Listen

PREGNETS

\section{Source}

Canadian Public Health Association

Best Start Resource Centre

Centre for Addiction and Mental Health

Clinical Tobacco Interventions (OMA, ODA, OPA

Motherisk (Hospital for Sick Children)

Ontario Tobacco Research Unit

Program Training and Consultation Centre

Smokers' Helpline

St. Joseph's Health Centre (Toronto)

Toronto Public Health

www.pregnets.org

\section{TABLE III}

\section{Directions for Programming in Canada ${ }^{11}$}

Recommended Developmental Directions for Smoking Cessation Programs for Pregnant Smokers

1. Increase tailoring: create programs that address the needs of different subpopulations of pregnant smokers

2. Incorporate women-centred approach: create internal motivation for cessation to decrease chances of relapse

3. Consider social context: assist the woman in dealing with the negative social stigma surrounding smoking in pregnancy

4. Focus on relapse prevention: follow up and support women into the postpartum period, when the chances for relapse are greatest

5. Incorporate harm reduction: encourage women who cannot quit to cut down

6. Incorporate social support: address smoking in the woman's immediate social environment

Obstetrics and Gynecological Clinics of North America 2001;28(2):269-82.

3. Miller WR. Motivational Interviewing: Research, Practice and Puzzles. Addict Behav 1996;21(6):835-42.

4. Prochaska JO, DiClemente CC, Norcross JC. In search of how people change. Applications to addictive behaviors. Am Psychologist 1992;47(9):1102-14.

5. Stotts AL, DiClemente CC, Carbonari JP, Mullen PD. Pregnancy smoking cessation: A case of mistaken identity Addict Behav 1996;21(4):459-71.

6. Edwards N, Edgley K, Kuhn M. Understanding Postpartum Smoking Relapse: Four Case Studies. Ottawa: Community Health Research Unit, 1997.

7. McNeil D, Welk K. Perinatal Smoking...Helping Women Change. British Columbia: Final Report Submitted to the Upper Island Central Coast Community Health Services Society, 1999. 
8. Browne A, Shultis J, Thio-Watts M. Solutionfocused approaches to tobacco reduction with disadvantaged prenatal clients. J Community Health Nursing 1999;16(3):156-77.

9. Flett Consulting Group, Inc. Evaluation of Kick Butt for 2/Maman, on écrase! Final Report. Prepared for: Young/Single Parents Support Network of Ottawa, 1997

10. Price JH, Krol RA, Desmond SM, Losh DP, et al. Comparison of three antismoking interventions among pregnant women in an urban setting: A randomized trial. Psychological Reports 1991;68(2):595-604.

11. Greaves L, Cormier R, Devries K, Bottorff J, Johnson J, Kirkland S, Aboussafy D. Expecting to Quit: A Best Practices Review of Smoking Cessation Interventions for Pregnant and Postpartum Girls and Women. British Columbia Centre of Excellence for Women's Health, Vancouver: Health Canada, 2003.

Received: December 3, 2003

Accepted: February 13, 2004

\section{Book Review}

\section{Federalism, Democracy and Health Policy in Canada \\ Duane Adams (Ed.) Montréal \\ (Québec): McGill-Queens University \\ Press, 2001;310 pp, \$65 (Cloth), \\ $\$ 29.95$ (Paper)}

Working in the past few years in the areas of healthy public policy (beyond the health care system) and the interface with democracy and equity, I have a special interest in this book. I read it with two questions in mind: 1) What evidence is there of public influence on the health system and health policies? and 2) Has policy helped to shift the health system to a more preventive approach?

The book is a compilation of papers from Canadian scholars through the Saskatchewan Institute of Public Policy from a three-year project focussing on the role of intergovernmental regimes and their effect on policy, federalism and democracy. Six case studies include national health goals; the Federal/Provincial/ Territorial conference system (strengths and weaknesses); cost containment in the federalist context; the health facility fees challenge; regionalization and national health surveillance. The 'technical' part of the analysis was based on defining a continuum of intergovernmental regimes ranging from 'federal unilateralism' (where little or no consultation with provinces occurs) to 'disentangled federalism' (where federal and provincial jurisdiction is mutually exclusive, independent and nonhierarchical) and the extent to which they were effective.

From a Public Health perspective, there was frank discussion throughout about the 'trade-offs' between the goal of good policy and what the (obviously strained) federalprovincial relationship can accommodate. The section by Adams on National Health Goals illustrates the challenge of jurisdictions and differing accountability. He concludes that the challenge of common goals is fundamentally about nation-building!

Patricia O'Reilly has a similar disappointing conclusion (The Canadian
Health System Landscape): "The established intergovernmental machinery, while being an amicable network of bureaucratic colleagues, has delivered very little new health policy to the country in the past decade apart from some new technical and system support programs and institutions such as the Canadian Institute for Health Information ..." Not surprisingly, she also describes evidence of the inter-governmental machinery as " secretive, allowing only a few select professionals and little public ...expertise into policy development".

On health surveillance, Kumanan Wilson comments on "ambiguous health jurisdictions, inefficiencies, duplications and gaps between federal and provincial partners in relation to indicators, capacities, reporting mechanisms which are well known to practitioners, and do pose a health risk to Canadians." This has, of course, been repeated in other findings, including the Romanow report.

While somewhat technical at times, for the most part the reading is straightforward and informative, even for the nonpolitical science person. The answer to my questions regarding public input was largely negative and, although not explicit, these scholars found little evidence that policy is moving toward population health, notwithstanding the rhetoric. While there is a lot of material here, it can be easily skimmed for the relevant sections. One disappointment was the lack of back index in order to search particular themes such as 'prevention'.

The reader is left with further evidence (if it were needed) that the present intergovernmental ill will needs to be addressed along with sustainable long-term federal funding for policy decision-making to begin to serve the interest of federalism, public interest, and effective health policy in Canada.

\section{David Swann MD, FRCP (Community Medicine) \\ Calgary, $A B$}

(Book Reviews continued on page 313) 